\title{
LABORATORY TESTING OF ACTIVE AND PASSIVE UHF RFID TAGS
}

\author{
Peter Kolarovszki ${ }^{1}$, Zuzana Kolarovszká ${ }^{2}$, Dragan Perakovic ${ }^{3}$, Marko Periša ${ }^{4}$ \\ ${ }^{1}$ University of Žilina, Faculty of operation and economics of transport and communications, \\ Department of communications, Slovakia \\ E-mail: kolarovszki@fpedas.uniza.sk, \\ ${ }^{2}$ University of Žilina, Faculty of operation and economics of transport and communications, \\ Department of communications, Slovakia \\ E-mail: zuzana.kolarovszka@fpedas.uniza.sk, \\ ${ }^{3}$ University of Zagreb, Faculty of Transport and Traffic Sciences \\ E-mail: dragan.perakovic@fpz.hr, \\ ${ }^{4}$ University of Zagreb, Faculty of Transport and Traffic Sciences \\ E-mail: marko.perisa@fpz.hr
}

\begin{abstract}
This article deals with research of laboratory testing by active and passive UHF tags and therefore mutual coexistence of active and passive RFID technology, which is a part of automatic identification and data capture. In this article we would like to describe an identification of transport unit based on passive technology and also by active technology. We would like to specify, how this technologies can work together and in which application focuses on postal and logistics. All results are verified by measurement in our AIDC laboratory, which is located at the University of Žilina. Our research contains different types of measurements in order to point out the possible influence of these two technologies. The results of our research bring the new point of view and indicate the ways using of UHF RFID technology in postal and logistics applications. At the end of this article is characterized the utilization of the RFID technology in postal logistics chain by using both passive and active technologies.
\end{abstract}

Keywords: RFID technology, active tag, passive tag, transport unit, identification

\section{Introduction}

Radio frequency identification is becoming a modern and useful in many sectors. It provides a contactless identification, tracking and tracing of goods, property and people in real time. Increase efficiency, performance and competitiveness. One area of application of RFID technology is also postal and logistic processes. In this context there are several question of feasibility of the use of identification of letters, parcels etc. In addition to the costs associated with the introduction of technology is necessary to examine the feasibility of using RFID technology in the field of postal and logistic processes.

Today, postal operations have implemented RFID in various closed-loop systems to measure, monitor, and improve operations. For example, RFID is being used to monitor international mail service between major hubs. By randomly "seeding" tagged letters into trays, elapsed delivery time can be measured. This allows service issues to be identified and addressed in a reliable and cost-effective manner. Other postal and also logistics companies have piloted tracking mail containers to measure trailer utilization and to track container locations. Manual container tracking systems tend to break down when volumes are high and there's a deadline to meet departure times. By allowing information to be captured automatically, RFID makes sure it is done, even under stressful conditions.

This article deals with research of mutual coexistence of active and passive RFID technology in the field of postal and logistics network optimization and transport processes. We performed research of readability of RFID identifiers attached to transport items.

\section{Objective and methodology}

Object of research were transport items (letter trays) and active, passive RFID tags placed into this transport units. RFID tags were read by active and passive RFID readers in several position and conditions. In order to achieve the relevant results of the research, more than 100 measurements were performed by various types of testing. We used several software programs to obtained data from RFID readers and also 
set different type of hardware configurations. First of all we defined problem named as: "How can works active and passive RFID technology in postal environments side by side". Thank we analyzed RFID technology in postal and logistics processes of course in conjunction with our field of research. After this we configure hardware and software platforms and started with our tests.

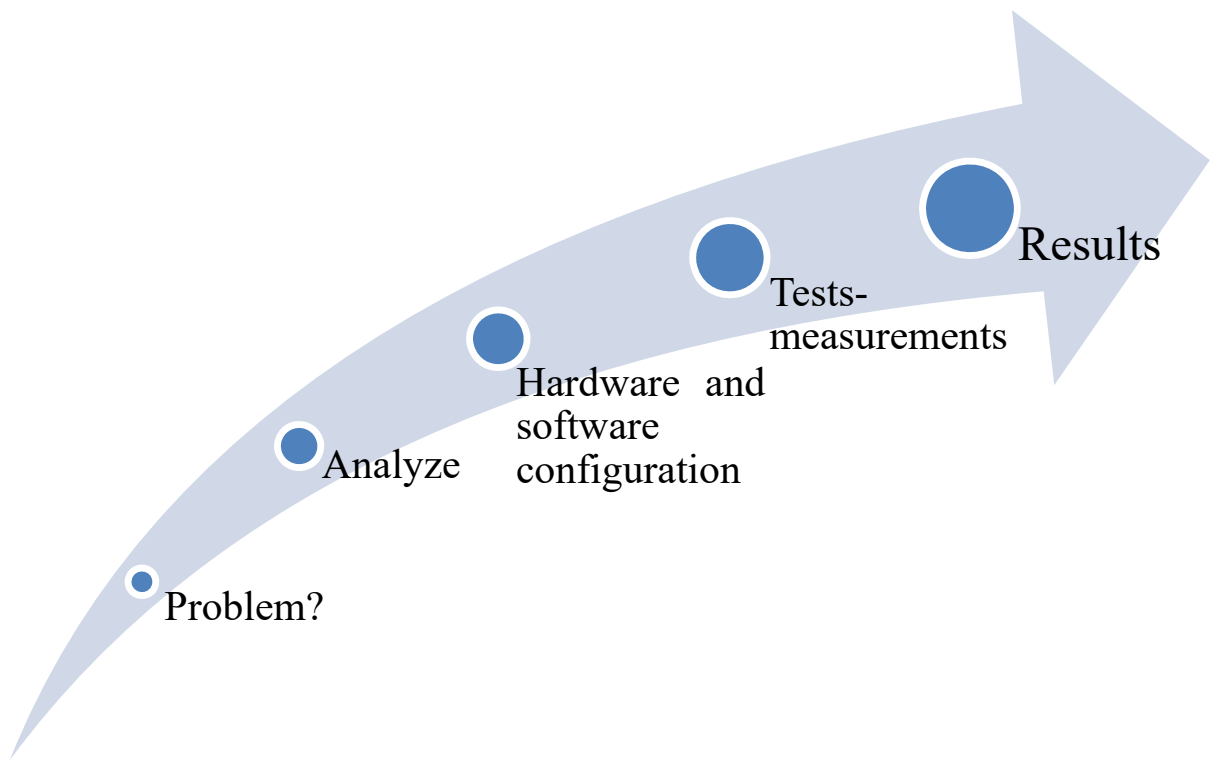

Figure 1. Steps to achieve good results

\section{RFID in postal and logistics processes}

The AMQM ${ }^{1}$ TM Platform provides postal operators with a complete overview and effective traceability of mail volumes, parcels, mail bags, mail items, trucks, roll-containers and letter trays across the entire logistics chain. One key feature is automatic consignment system that associates the mail items to the containers carrying these items and to the trucks transporting these.

This solution can be based on various technologies such as: RFID (Hunt, Puglia, 2007), disposable RFID labels and bar codes, as well as combinations thereof. It also enable objective documentation of times of arrival and departure of vehicles, which postal containers are loaded/unloaded, vehicle load space management, real-time information on types of mail, quantities, times of arrival, delays or changes in transport times etc. (Beneš et al., 2013) With regard to postal operational systems, the following conditions must be taken into account:

- $\quad$ Rough industrial environments.

- Large volumes of goods and mail.

- Short time available for processing.

- High labor costs in connection with the daily operations.

- Large potentials in automation and streamlining of manual processes.

\subsection{RFID-based Vehicle Management}

Tracking vehicles and trailers throughout the entire transport logistics chain provides considerable benefits to all parties involved, e.g. management, users and customers. The Vehicle and Trailer Tracking System is an advanced and effective IT system for monitoring and managing precise arrivals and departures of vehicles at specific points in the logistics chain. The system is built on the experience and know-how acquired from supplying the world's largest and most widespread RFID network stretching across about 60 countries. (Kendra et al., 2012)

Implementing this system offers unique values. Examples of benefits:

- Fully automatic registration of vehicles - i.e. no manual work involved.

- Improved yard and vehicle management.

\footnotetext{
${ }^{1} \mathrm{AMQM}$ - Automatic Mail Quality Measurement
} 
- $\quad$ Precise and objective record of exchange of goods between parties.

- Early warning on delays in transport to all parties.

- Precise feedback to transport planning systems.

- Improved vehicle maintenance routines.

- Cost savings in centers with real-time information available.

\subsection{Roll Cage Tracking and managing}

One of the main issues being addressed by the roll container tracking and managing project is need to take control of and better manage transportation assets. Another primary project requirement is to ensure that the required containers will be always available at the customers' premises and within postal operator facilities. This should overcome the tendency for planned or unplanned hoarding of roll containers that causes shortages elsewhere, especially at peak times. Additionally, the lack of visibility of roll container whereabouts led to unnecessary loss since it was not possible to identify where the roll containers disappeared and hence forced expensive purchase of new roll containers to meet the customer service level agreements. System of the monitoring and managing roll cages includes tag (active or passive, it depends of application), that is placed on a side or on the bottom of the container (Figure 2), it also includes a handheld terminal solution for consignment of roll container, product and destination enabling load control on all roll containers (Figure 3). (Klapita, Mašek, 2012)

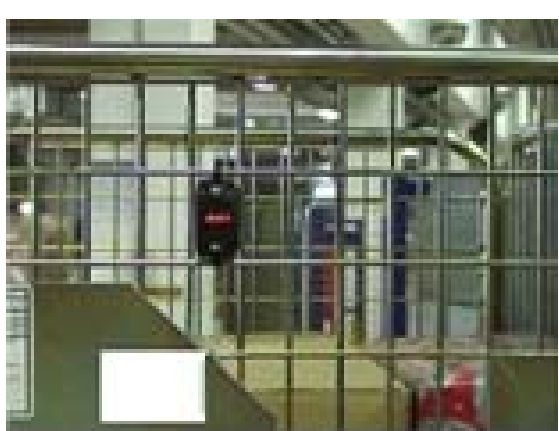

Figure 2. RFID tag placed on the container

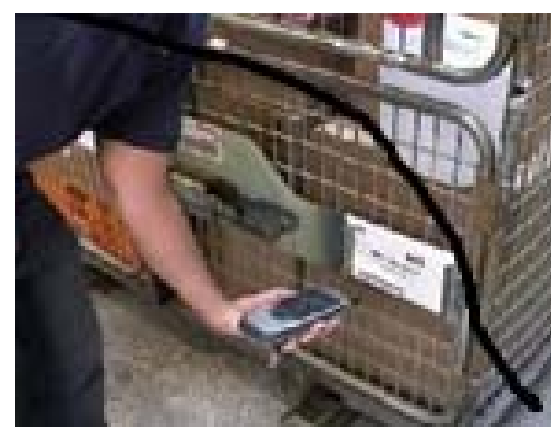

Figure 3. Handheld terminal

The result is avoiding miss-sending and has real-time $t$ volume forecasting into all facilities in the network providing efficient and on time production and distribution. Also a handheld terminal solution designed for track and trace of all individual parcels is a part of the solution providing key customers with shipment visibility throughout the whole logistic network. Miss-shipments are prevented by load-control.

When a roll container is ready for dispatch, the roll container is scanned for destination and product type. If the roll container is lead through a gate not matching the destination, an alert will immediately help correct the mistake. Solution must include Asset Management software platform enabling full, real-time transparency of the location of each roll container and can be also used to track specific mail and parcel transports. Implementing this system offers unique values. Examples of benefits:

- Improves availability and load balance throughout the logistics chain.

- Prevents hoarding of roll-containers.

- Minimizes losses.

- Helps to improve supply chain efficiency.

- Provides the ability to monitor the transported delivery time of goods.

- Helps to improve service and maintenance.(Vaculík, Tengler, 2012)

\subsection{Letter Tray Tracking}

Tracking and tracing letter trays throughout the entire postal logistics chain provides benefits to postal customers, employees and management. The trays are automatically registered in the postal logistics by means of RFID technology. Each letter tray has a tag that communicates and transmits information to the reader in Real-time load control (Figure 4). Now it is possible for the postal operators to reuse the same RFID network to track \& trace postal letter trays. This new opportunity is a fast pay-back investment with many unique advantages to postal operators worldwide. 


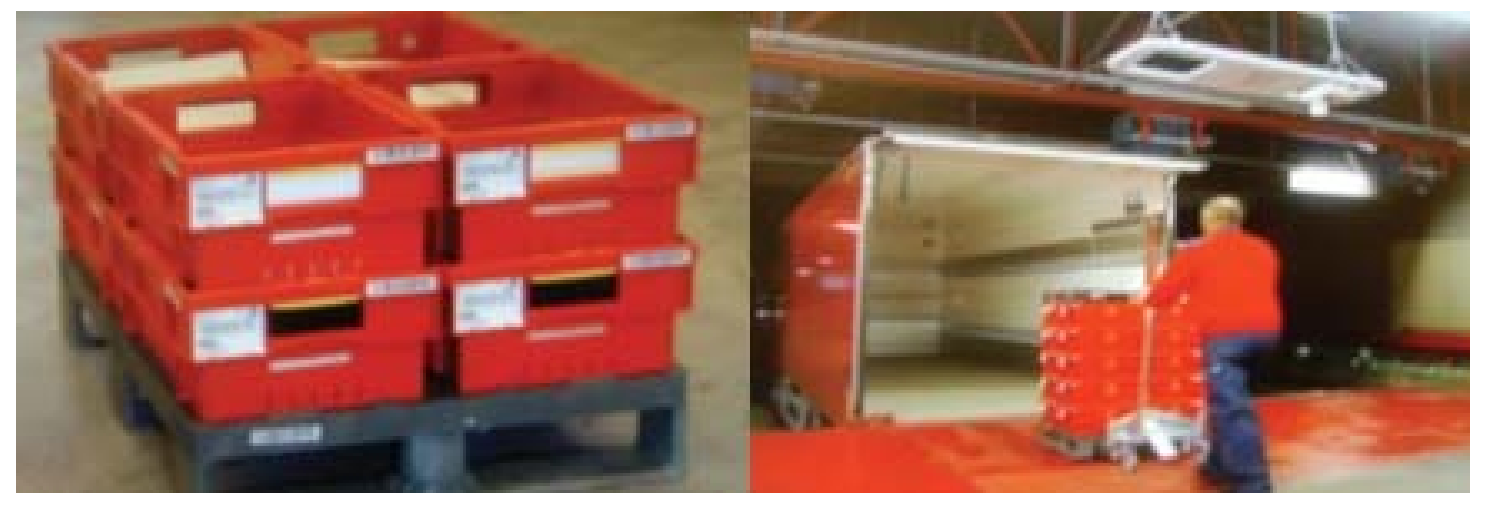

Figure 4. RFID tags on letter trays and Real-time load control

Key Benefits:

- Better utilization of postal letter trays.

- Possibility to analyze through-put times of mail and letter trays at distribution center.

- Knowing the location of trays improves their availability throughout the entire logistics chain.

- Knowing the location and contents of trays improves the possibility of managing the tray sorting process right on time.

- On automatic handling systems, such as tray sorters, the reading rate can be improved dramatically compared to that of bar codes - reducing manual intervention.

- Being able to identify trays helps to improve service and maintenance.

\section{RFID components used in measurements}

The RFID system architecture consists of a reader and a tag (also known as a label or chip). The reader queries the tag, obtains information, and then takes action based on that information. That action may display a number on a hand held device, or it may pass information on to a POS system, an inventory database or relay it to a backend payment system thousands of miles away. Let's looks at some of the basic components we have used in our research.

\subsection{RFID tags used in measurements}

An RFID tag is a small device that can be attached to an item, case, container, or pallet, so it can be identified and tracked. It is also called a transponder. The tag is composed of microchip and antenna. These elements are attached to a material called a substrate in order to create an inlay.

Tags are categorized into three types based on the power source for communication and other functionality.

- Active.

- Passive.

- Semi-passive.

- Semi-active

We have used special active RFID tags used in postal and logistics environment, which can works at different modules:

- Broadcast ID at predefined intervals (heart beat and long range approximate tag location information).

- Broadcast ID along with exciter ID when activated by an LS exciter (short range defined tag location information).

- Broadcast ID when the tag is in motion (vibration sensor activates the tag and indicates the asset is on the move). (Thornton, Lanthem, 2006) 


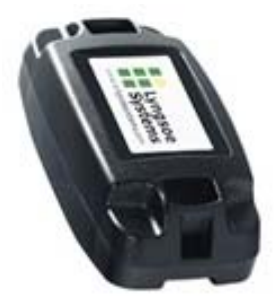

Figure 5. Active RFID tag

Than we also know special postal semi active RFID tags, used in case of measurements of quality services. This type of tags are able to work on two different frequencies (125 KHz and $433 \mathrm{MHz}$ ). This type of RFID tags are placed into the envelope and send it through all postal logistic chain. It can happened that, this type of tags will be side by side with passive UHF tags, which are used in postal sector to identifying high added value letters or parcels, containers and also letter trays.

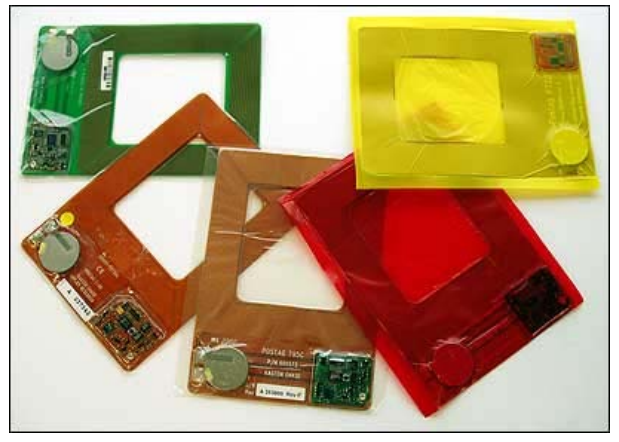

Figure 6. Semi active postal RFID tags

\subsection{RFID Portal used in measurements}

In our laboratory we have a special RFID portal combines two technologies (active and passive). It consists of passive Impinj RFID reader, which we used in measurements due to passive RFID tags and also active reader used in conjunction with active tags. We have a special software solution for active part of the portal and also for passive part of the portal.

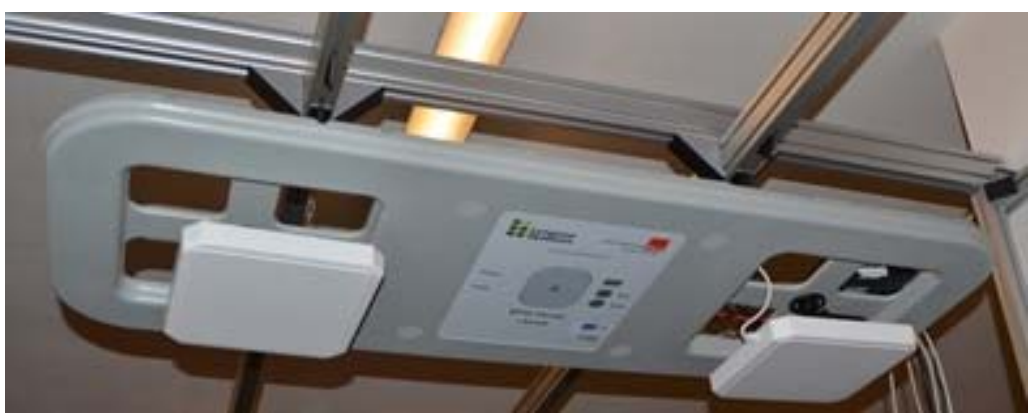

Figure 7. Combine RFID active and passive portal

\subsection{RFID Middleware}

Middleware is software that controls the reader and the data coming from the tags and moves them to other database systems. It carries out basic functions, such as filtering, integration and control of the reader. RFID systems work, if the reader antenna transmits radio signals. These signals are captured tag, which corresponds to the corresponding radio signal. This is a very special software device enabling mutual communication between two and more applications. This device is marked also as a mediator between various application components.

We have used two middleware platforms, one from company Aton AMP, that consist of several processors programmed in Java and second one from Lyngsoe systems named as EDECS (see Figure 8). (Vojtěch, Neruda, 2010) 


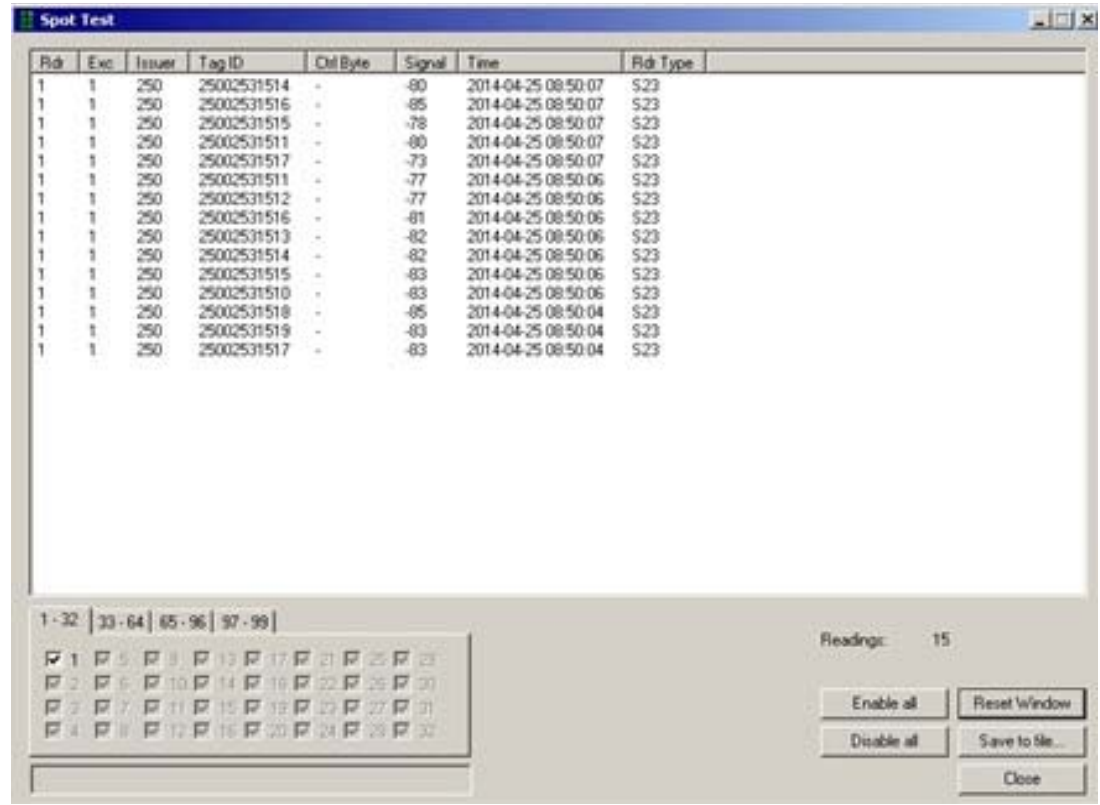

Figure 8. EDECS middleware

\section{Description of measurements and AMP model configuration}

In order to achieve relevant outcomes, it was inevitable at first to design functional system enabling realization of single measurements under laboratory conditions. In order to comprehend single measurements, we have to define the principle they operate under and what is being detected by them.

\subsection{AMP model configuration}

Configuration of the model for readability measurement of passive tags was designed in environment of AMP middleware. Configuration in AMP ensures communication between hardware and software part of our model. At the same time, it enables to set up the configuration itself, so by its use we define practically what, how and when should the particular hardware and software components operate. Our configuration (Figure 9) consists of several processors:

- LLRPProcessor

- EarlyDecoupler

- TimeFormatter2

- WhitelistFilter

- InsertProcessor
- MessageTransformer

- LoggerNeW

- $\mathrm{db}$ - connection to database

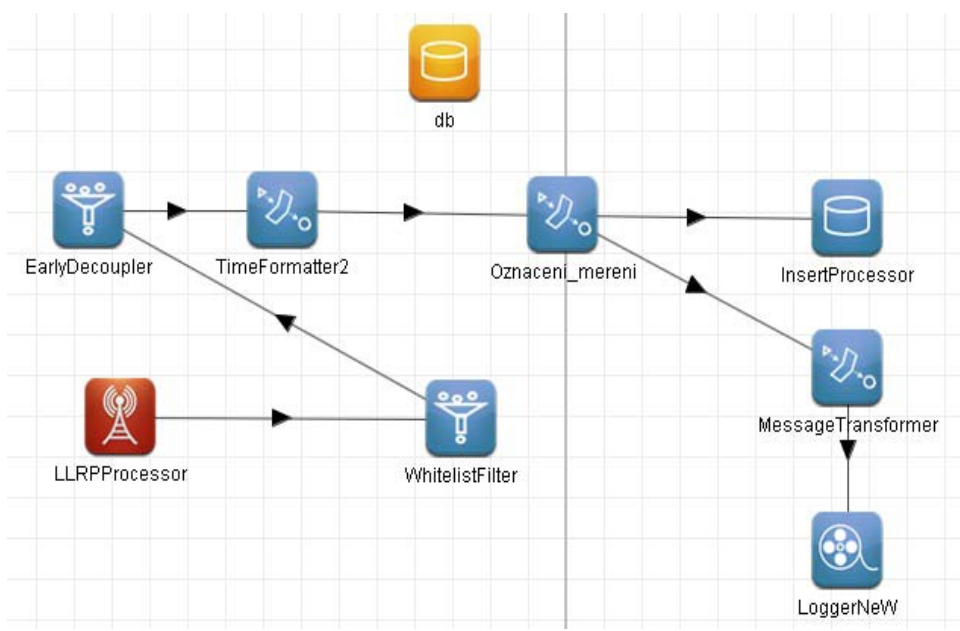

Figure 9. AMP Configuration 


\subsection{Description of measurements}

At first, we have to find out the readability of passive and active RFID tags of letter trays placed in metal postal container at the moment of its passing through RFID gate with antennas. At second, we have to realize that we perform several types of measurements. These types differ in RFID tags orientation on letter trays and also different environment conditions as well as combination active and passive RFID tags placing together. Each of active and passive RFID tags was placed in one of the 10 postal crate placed in to postal container. (Madleňák et al., 2015)

We performed several types of measurements:

1. Placement of active container tag CT 23 and passive RFID tag in to the postal crate,

2. Placement of active container tag CT 23 and passive RFID tag in to the postal crate together with bottles with water,

3. Placement of active PT 23 letter tags abreast to passive tags.
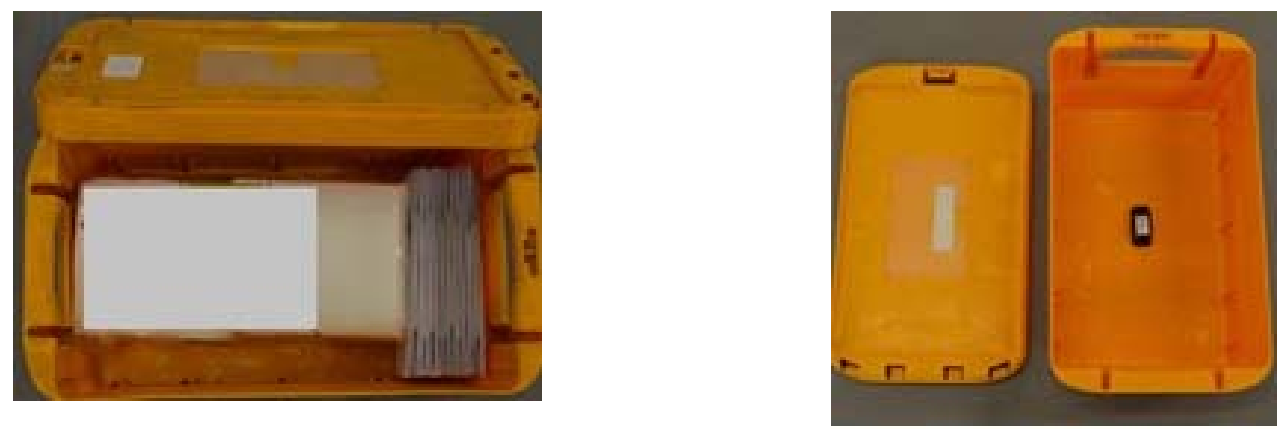

Figure 10. Example of placing booth passive and active tags in third and first measurements

\section{Results from the measurements}

In this chapter we gradually describe the results of individual measurements and correct conclusions from them. The individual measurements were investigated readability of RFID identifiers.

\section{Placement of active container tag CT 23 and passive RFID tag in to the postal crate}

In this type we added into crates active and passive RFID tags. These were inserted inside the postal crates. We used 10 passive and active tags. Results are clearly described in the Figure 11. In following tables we use just last 3 not null digits of the tags.

Table 1. RSSI values of passive tags obtained in second measurement

\begin{tabular}{|c|c|c|c|c|c|c|c|c|c|c|c|c|c|c|c|c|c|c|c|c|c|}
\hline \multirow[b]{2}{*}{ Tag ID } & \multicolumn{20}{|c|}{ Signál RSSI } & \multirow{2}{*}{\begin{tabular}{|c|} 
priemer \\
$\mathrm{dB}$ \\
\end{tabular}} \\
\hline & - & $\mathrm{dB}$ & - & $\mathrm{dB}$ & - & $\mathrm{dB}$ & - & $\mathrm{dB}$ & - & $\mathrm{dB}$ & - & $\mathrm{dB}$ & - & $\mathrm{dB}$ & - & $\mathrm{dB}$ & - & $\mathrm{dB}$ & - & $\mathrm{dB}$ & \\
\hline 9 & -61 & 34 & -60 & 35 & -61 & 34 & -51 & 44 & -64 & 31 & -52 & 43 & -61 & 34 & -55 & 40 & -61 & 34 & -60 & 35 & 36,4 \\
\hline 14 & -60 & 35 & -58 & 37 & -65 & 30 & -54 & 41 & -63 & 32 & -51 & 44 & -62 & 33 & -56 & 39 & -56 & 39 & -64 & 31 & 36,1 \\
\hline 16 & -50 & 45 & -55 & 40 & -54 & 41 & -57 & 38 & -55 & 40 & -56 & 39 & -53 & 42 & -55 & 40 & -62 & 33 & -55 & 40 & 39,8 \\
\hline 18 & -66 & 29 & -59 & 36 & -69 & 26 & -69 & 26 & -70 & 25 & -60 & 35 & -69 & 26 & -59 & 36 & -58 & 37 & -70 & 25 & 30,1 \\
\hline 20 & -60 & 35 & -57 & 38 & -58 & 37 & -60 & 35 & -57 & 38 & -60 & 35 & -57 & 38 & - & 0 & -58 & 37 & -58 & 37 & 33 \\
\hline 27 & -62 & 33 & -58 & 37 & -60 & 35 & -58 & 37 & -60 & 35 & -62 & 33 & -59 & 36 & - & 0 & -58 & 37 & -61 & 34 & 31,7 \\
\hline 32 & -54 & 41 & -57 & 38 & -55 & 40 & -61 & 34 & -51 & 44 & -58 & 37 & -50 & 45 & - & 0 & -60 & 35 & -53 & 42 & 35,6 \\
\hline 33 & -63 & 32 & -58 & 37 & -62 & 33 & -54 & 41 & -62 & 33 & -55 & 40 & -65 & 30 & -62 & 33 & -62 & 33 & -62 & 33 & 34,5 \\
\hline 37 & -60 & 35 & -55 & 40 & -52 & 43 & -60 & 35 & -61 & 34 & -55 & 40 & -57 & 38 & -54 & 41 & -53 & 42 & -60 & 35 & 38,3 \\
\hline 39 & -55 & 40 & -53 & 42 & -58 & 37 & -56 & 39 & -62 & 33 & -58 & 37 & -61 & 34 & -54 & 41 & -58 & 37 & -61 & 34 & 37,4 \\
\hline Čitatel'nost' & $100 \%$ & & $100 \%$ & & $100 \%$ & & $100 \%$ & & $100 \%$ & & $100 \%$ & & $100 \%$ & & $70 \%$ & & $100 \%$ & & $100 \%$ & & $97 \%$ \\
\hline
\end{tabular}


Table 2. RSSI values of active tags obtained in second measurement

\begin{tabular}{|c|c|c|c|c|c|c|c|c|c|c|c|c|c|c|c|c|c|c|c|c|c|}
\hline \multirow[b]{2}{*}{ Tag ID } & \multicolumn{20}{|c|}{ Signál RSSI } & \multirow{2}{*}{$\frac{\text { priemer }}{\mathrm{dB}}$} \\
\hline & - & $\mathrm{dB}$ & - & $\mathrm{dB}$ & - & $\mathrm{dB}$ & - & $\mathrm{dB}$ & - & $\mathrm{dB}$ & - & dB & - & $\mathrm{dB}$ & - & $\mathrm{dB}$ & - & $\mathrm{dB}$ & - & dB & \\
\hline 510 & -74 & 21 & -72 & 23 & -71 & 24 & -74 & 21 & -72 & 23 & -75 & 20 & -71 & 24 & -76 & 19 & -72 & 23 & -64 & 31 & 22,9 \\
\hline 512 & -65 & 30 & - & 0 & - & 0 & - & 0 & -65 & 30 & -65 & 30 & -64 & 31 & - & 0 & -64 & 31 & -65 & 30 & 18,2 \\
\hline 515 & -70 & 25 & -70 & 25 & -72 & 23 & -69 & 26 & - & 0 & -69 & 26 & - & 0 & - & 0 & - & 0 & -66 & 29 & 15,4 \\
\hline 516 & -80 & 15 & -68 & 27 & -69 & 26 & -76 & 19 & -69 & 26 & -69 & 26 & - & 0 & -76 & 19 & -73 & 22 & -71 & 24 & 20,4 \\
\hline 517 & -70 & 25 & -71 & 24 & -74 & 21 & -70 & 25 & -65 & 30 & -72 & 23 & -72 & 23 & -72 & 23 & -72 & 23 & -70 & 25 & 24,2 \\
\hline 519 & -71 & 24 & -69 & 26 & -70 & 25 & -73 & 22 & -69 & 26 & -72 & 23 & -78 & 17 & -73 & 22 & -69 & 26 & -72 & 23 & 23,4 \\
\hline 521 & -70 & 25 & -73 & 22 & -72 & 23 & -70 & 25 & -81 & 14 & -70 & 25 & -72 & 23 & -69 & 26 & -78 & 17 & -74 & 21 & 22,1 \\
\hline 522 & -70 & 25 & -78 & 17 & -77 & 18 & -70 & 25 & -76 & 19 & -70 & 25 & -76 & 19 & -71 & 24 & -69 & 26 & -72 & 23 & 22,1 \\
\hline 523 & -83 & 12 & -70 & 25 & -70 & 25 & -81 & 14 & -76 & 19 & -83 & 12 & -71 & 24 & -85 & 10 & -68 & 27 & -67 & 28 & 19,6 \\
\hline 524 & -78 & 17 & -71 & 24 & -67 & 28 & -79 & 16 & -70 & 25 & -72 & 23 & -67 & 28 & -73 & 22 & -77 & 18 & -80 & 15 & 21,6 \\
\hline Čitatel'nost' & $100 \%$ & & $90 \%$ & & $90 \%$ & & $90 \%$ & & $90 \%$ & & $100 \%$ & & $80 \%$ & & $80 \%$ & & $80 \%$ & & $100 \%$ & & $90 \%$ \\
\hline
\end{tabular}

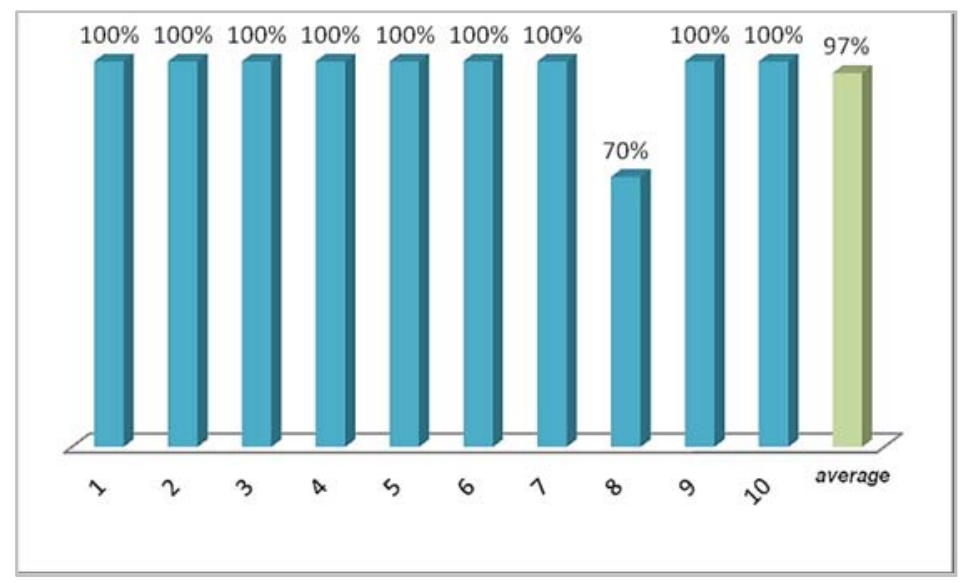

Figure 11. Result of readability of passive tags

As we can see in only one measurement we did not achieved $100 \%$ of readability. Passive RFID identifiers with number 20, 27 and 32 was not read correctly. All others were read with any problems. In conjunction with active tags we can say that not all of them were read. On the Figure 12 we can see, that many of active RFID identifiers had a problem with readability and with RSSI values.

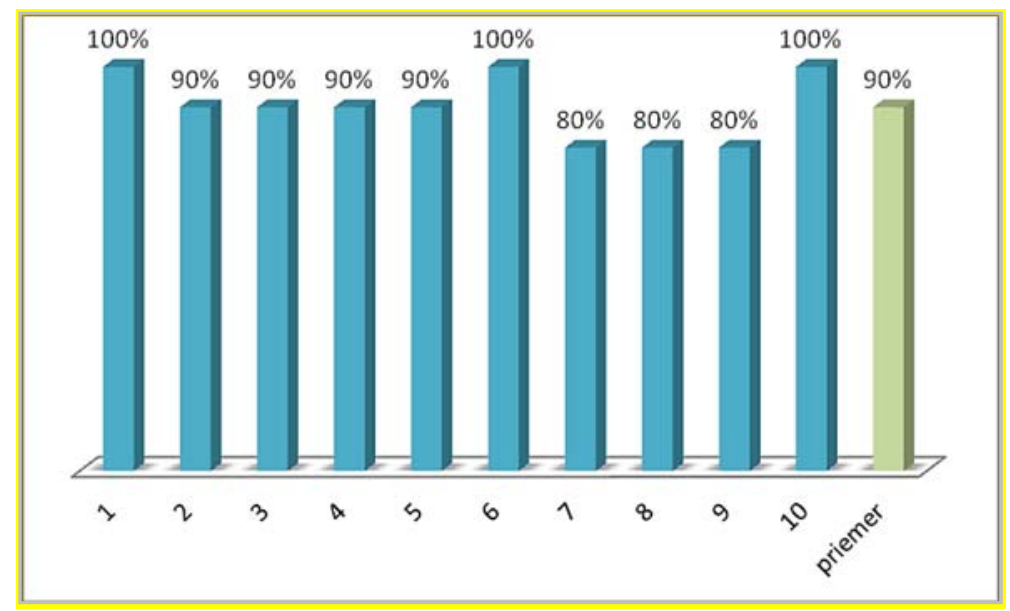

Figure 12. Result of readability of passive tags

\section{Placement of active container tag CT 23 and passive RFID tag in to the postal crate together with bottles with water}

In this type we added into crates active and passive RFID tags, but we added also two bottles $(1,5 \mathrm{~L})$ to each postal crate (see Figure 13$)$. We used again 10 passive and active tags. Results are clearly described in the Figure 14. 


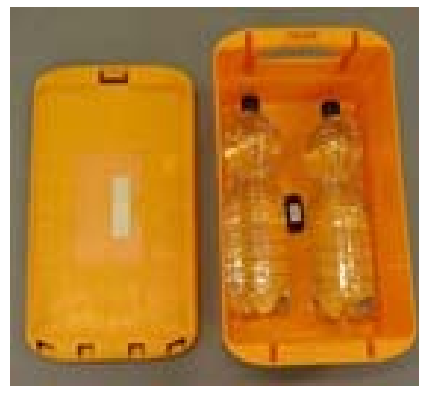

Figure 13. Placement of passive and active tags in second measurement

Table 3. RSSI values of passive tags obtained in sixth measurement

\begin{tabular}{|c|c|c|c|c|c|c|c|c|c|c|c|c|c|c|c|c|c|c|c|c|c|}
\hline \multirow[b]{2}{*}{ ag ID } & \multicolumn{20}{|c|}{ Signál RSSI } & \multirow{2}{*}{\begin{tabular}{|c|} 
priemer \\
$\mathrm{dB}$ \\
\end{tabular}} \\
\hline & - & dB & - & dB & - & dB & - & $\mathrm{dB}$ & - & $\mathrm{dB}$ & - & dB & - & $\mathrm{dB}$ & - & $\mathrm{dB}$ & - & $\mathrm{dB}$ & - & $\mathrm{dB}$ & \\
\hline 9 & -58 & 37 & -58 & 37 & -58 & 37 & -60 & 35 & -58 & 37 & -59 & 36 & -57 & 38 & -59 & 36 & -56 & 39 & -58 & 37 & 36,9 \\
\hline 14 & -59 & 36 & -60 & 35 & -59 & 36 & -59 & 36 & -60 & 35 & -60 & 35 & -60 & 35 & -61 & 34 & -60 & 35 & -59 & 36 & 35,3 \\
\hline 16 & -60 & 35 & -61 & 34 & -61 & 34 & -59 & 36 & -57 & 38 & -61 & 34 & -62 & 33 & -61 & 34 & -59 & 36 & -60 & 35 & 34,9 \\
\hline 18 & -59 & 36 & -66 & 29 & -61 & 34 & -69 & 26 & -58 & 37 & -66 & 29 & -60 & 35 & -68 & 27 & -62 & 33 & -61 & 34 & 32 \\
\hline 20 & - & 0 & -55 & 40 & - & 0 & - & 0 & - & 0 & -55 & 40 & -55 & 40 & - & 0 & - & 0 & -61 & 34 & 15,4 \\
\hline 27 & - & 0 & - & 0 & - & 0 & - & 0 & - & 0 & - & 0 & - & 0 & - & 0 & - & 0 & -62 & 33 & 3,3 \\
\hline 32 & -56 & 39 & -58 & 37 & -56 & 39 & -57 & 38 & -55 & 40 & -56 & 39 & -54 & 41 & -57 & 38 & -54 & 41 & -54 & 41 & 39,3 \\
\hline 33 & -60 & 35 & -57 & 38 & -61 & 34 & -55 & 40 & -60 & 35 & -60 & 35 & -62 & 33 & -61 & 34 & -60 & 35 & -60 & 35 & 35,4 \\
\hline 37 & - & 0 & - & 0 & - & 0 & - & 0 & -57 & 38 & - & 0 & - & 0 & & 0 & & 0 & -60 & 35 & 7,3 \\
\hline 39 & -55 & 40 & -55 & 40 & -54 & 41 & -55 & 40 & -54 & 41 & -55 & 40 & -54 & 41 & -54 & 41 & -55 & 40 & -55 & 40 & 40,4 \\
\hline & $70 \%$ & & $80 \%$ & & $70 \%$ & & $70 \%$ & & $80 \%$ & & $80 \%$ & & $80 \%$ & & $70 \%$ & & $70 \%$ & & $100 \%$ & & $77 \%$ \\
\hline
\end{tabular}

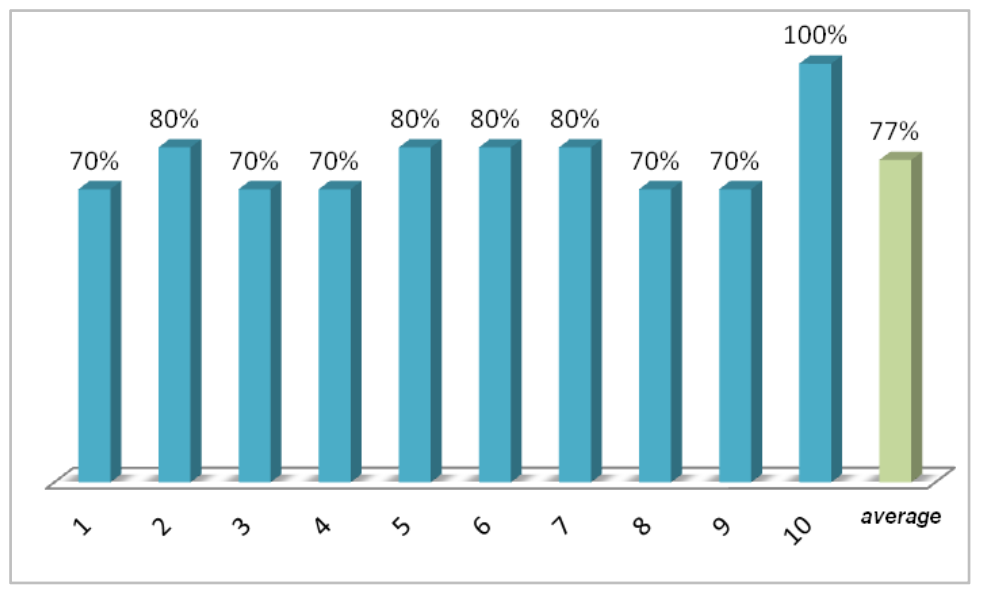

Figure 14. Result of readability of passive tags

As we can see, the presence of bottles of water significantly affected the readability of passive RFID identifiers. The average of readability was just $77 \%$. In terms of active identifiers, all ten were read similarly as in the previous case.

\section{Placement of active PT 23 letter tags abreast to passive tags}

In this type we added to passive tags also active RFID tags used in AMQM measurements. These were inserted inside the postal crates. We used 10 passive and active tags. We placed passive and active tags as follow:

$<$ passive tag + active tag + passive tag + active tag $+\ldots \ldots . .>$, until we reached 10 active tags.

Between each tags was no space, so it was very similar as in real conditions. On Figure 15 we can see results of this type of measurements. 
Table 4. RSSI values of passive tags obtained in sixteen measurement

\begin{tabular}{|c|c|c|c|c|c|c|c|c|c|c|c|c|c|c|c|c|c|c|c|c|c|}
\hline \multirow[b]{2}{*}{ Tag ID } & \multicolumn{20}{|c|}{ Signál RSSI } & \multirow{2}{*}{\begin{tabular}{|c|} 
priemer \\
$\mathrm{dB}$ \\
\end{tabular}} \\
\hline & - & dB & - & dB & - & dB & - & dB & - & dB & - & dB & - & dB & - & dB & - & dB & - & dB & \\
\hline 8 & -59 & 36 & -62 & 33 & -62 & 33 & -62 & 33 & -60 & 35 & -60 & 35 & -61 & 34 & -61 & 34 & -60 & 35 & -62 & 33 & 34,1 \\
\hline 11 & -60 & 35 & -60 & 35 & -59 & 36 & -60 & 35 & -58 & 37 & -60 & 35 & -60 & 35 & -59 & 36 & -58 & 37 & -59 & 36 & 35,7 \\
\hline 19 & -56 & 39 & -59 & 36 & -54 & 41 & - & 00 & -55 & 40 & -56 & 39 & -57 & 38 & -57 & 38 & -57 & 38 & -56 & 39 & 34,8 \\
\hline 21 & -54 & 41 & - & 00 & -55 & 40 & - & 00 & -53 & 42 & - & 00 & -56 & 39 & - & 00 & - & 00 & - & 00 & 16,2 \\
\hline 23 & -58 & 37 & -56 & 39 & -58 & 37 & -56 & 39 & -55 & 40 & -55 & 40 & -52 & 43 & -56 & 39 & -55 & 40 & -56 & 39 & 39,3 \\
\hline 24 & -56 & 39 & - & 00 & -54 & 41 & - & 00 & -56 & 39 & - & 00 & -55 & 40 & - & 00 & - & 00 & -56 & 39 & 19,8 \\
\hline 26 & -58 & 37 & -59 & 36 & -61 & 34 & -59 & 36 & $\begin{array}{ll}-58 \\
\end{array}$ & 37 & -60 & 35 & -58 & 37 & -58 & 37 & -59 & 36 & -57 & 38 & 36,3 \\
\hline 29 & - & 00 & - & 00 & -55 & 40 & - & 00 & - & 00 & - & 00 & - & 00 & - & 00 & - & 00 & - & 00 & 4 \\
\hline 34 & -59 & 36 & -59 & 36 & -57 & 38 & - & 00 & -58 & 37 & -57 & 38 & -57 & 38 & -58 & 37 & - & 00 & -57 & 38 & 29,8 \\
\hline 35 & -55 & 40 & -55 & 40 & -56 & 39 & -55 & 40 & -55 & 40 & -55 & 40 & -57 & 38 & -56 & 39 & - & 00 & -56 & 39 & 35,5 \\
\hline 40 & -54 & 41 & - & 00 & -55 & 40 & - & 00 & -55 & 40 & - & 00 & -53 & 42 & -56 & 39 & -56 & 39 & -57 & 38 & 27,9 \\
\hline Čitatel'nost' & 90,91 & & 63,64 & & 100 & & 45,45 & & 90,91 & & 63,64 & & 90,91 & & 72,73 & & 54,55 & & 81,82 & & 75,45 \\
\hline
\end{tabular}

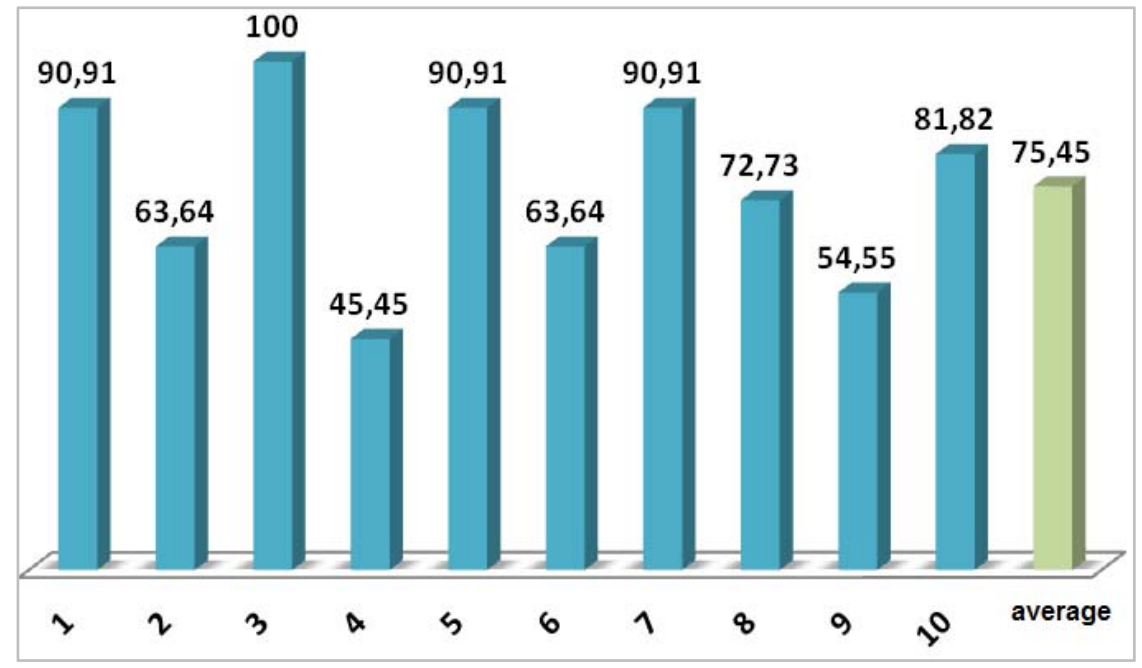

Figure 15. Result of readability of passive tags

On this figure are graphically shown just passive tags, because active tags obtained $100 \%$ of readability. As we can see 4 passive RFID tags obtained less than $70 \%$ of readability. This result was due to the interference of active RFID identifiers that were placed close to the passive tags.

\section{Conclusion}

We can state, that utilization of active radio frequency identification of postal crates or letters (testing letters) in postal operation is technically feasible as a very high level of readability was achieved by scanning of particular crates and letters under laboratory conditions. The results of placing passive RFID tags together with active tags are very dependent indeed on specific placement of passive RFID tags. As we can saw at the results the presence of active RFID identifiers led to interference of passive identifiers. Obviously polarization orientation and tags is also important, but in our case we have considered a horizontal orientation with respect to the deployment tag antenna of the reader. Due to usability measurement in practice we set a statistical significant value measurement for the readability of $99 \%$.

Due to this research result we can say that we can use passive technology for identification of postal crates, parcel an also post containers but identification letters is very complicated. In conjunction with placing of active RFID test letters together with passive identifiers leading to possible interference on the part of active tags.

\section{References}

1. Hunt, V., Puglia, A. and Puglia M. (2007) RFID: A Guide to Radio Frequency Identification. New Jersey (USA), John Wiley \& Sons, Inc. 201 p. 
2. Thornton, F., Lanthem, Ch. (2006) RFID Security. Rockland (MA, USA), Syngres Publishing, Inc. 229 p.

3. Vojtěch, L., Neruda, M. ( 2010) Application of Shielding Textiles for Increasing Safety Airborne Systems - Limitation of GSM Interference. The Ninth International Conference on Networks (ICN 2010). Los Alamitos: IEEE Computer Society, p.157-161.

4. Beneš, F., Kubáč, L., Staša, P., Kebo, V. (2013) RFID and Augmented Reality; Proceedings of the 14th International Carpathian Control Conference (ICCC): Rytro, Hotel Perła Południa, Poland, May 26-29, .p. 186-191.

5. Vaculík, J.,Tengler, J. (2012) Potential of new technologies in logistics services. CLC 2012 Carpathian logistics congress: November 7th-9th , Jesenik, Czech Republic,

6. Kendra, M., Lalinská, J., Čamaj, J. (2010) Optimalization of transport and logistics processes by simulation. In ISTEC; Proceedings of the 3rd International Science, Technology and Engineering Conference, Dubai, United Arab Emirates (UAE), December 13-15, (pp. 886-892).

7. Klapita, V., Mašek, J. (2012) Processes solution in the warehouse by the queuing theory application. In Horizons of Railway Transport: scientific papers (pp. 64-6). Vol. 3, no. 1.

8. Madleňák R., Madleňáková L., Štefunko J. (2015) The variant approach to the optimization of the postal transportation network in the conditions of the Slovak Republic, Transport and Telecommunication, Vol. 16 (3), pp. 237-245

9. Kolář, P., Rodrigue, J.-P. (2014) Improving the Bottlenecks: The Czech Republic as a Central European Intermodal Transport and Logistics Platform. IAME Conference 2014. Norfolk: Maritime Institute, Old Dominion University.

This article was created to support project named as:
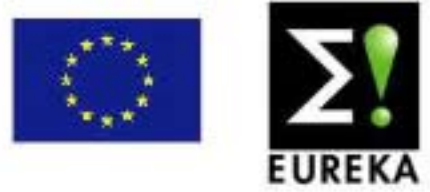

E!7592 AUTOEPCIS - RFID Technology in Logistic Networks of Automotive Industry

Centre of Excellence for Systems and Services of Intelligent Transport II ITMS 26220120050 supported by the Research \& Development Operational Programme funded by the ERDF. 